\title{
USING SOCIAL MEDIA TO ENHANCE STUDENT ENGAGEMENT AND QUALITY
}

\author{
R. A. Lottering \\ Computer Science Department \\ Tshwane University of Technology \\ Pretoria, South Africa \\ e-mail: lottering.roy@gmail.com / https://orcid.org/0000-0002-9348-3448
}

\section{ABSTRACT}

The educational benefits, which accrue from the enhancement in student engagement, are well documented in the literature. Some of the benefits identified include increased student interest in course content, enhanced academic performance and enhanced student critical thinking skills. This study demonstrates a significant advantage in using social media platforms in student engagement with the course material and lecturers offering the material. Typically, student engagement has been and mainly is achieved as on-campus contact mode or contact at sites of delivery and even online, using platforms created and managed by universities such as Blackboard. In this study, a comparative review of the academic performance of two groups of students enrolled for a similar subject offered at a University of Technology is performed to analyze the effects of using social media as a method to engage students on performance outside the normal communication time. The assumption is that this method of student engagement would enrich the student experience and alter how course content is articulated, presented and absorbed, in essence allowing the student to feel enabled and included in the engagement paradigm. Feedback provided in the engagement with peers and the lecturer leads to clarity and improvement in the quality of the course overall.

Keywords: student engagement, performance, academic success, data analytics, student involvement, enhancement

\section{INTRODUCTION}

Student engagement has been afforded significant transformation at the turn of the millennium as "Web 2.0" became more prevalent. This is due to the change in which users are allowed to interact with websites and online platforms. This enhanced and widened social paradigm enabled users to actively engage in the creation, manipulation and sharing of content at a much faster pace and larger scale. Such "new" ways of producing, communicating and distributing collaborative content mark a major departure from traditional passive viewing and content consumption. Social media platforms thrive on users' active engagement in manipulating and distributing content (Kuh et al. 2007). 
Student engagement features prominently in literature. It has been researched by many authors and a plethora of definitions and views are found in the literature. Although the technological advancements are fairly recent, the paradigm shift is well documented as is also demonstrated in this article.

A University of Technology (UoT) was used for the study, to evaluate student engagement based on the consumption of material measured in a prescribed course, its impact on performance and the overall anecdotal improvement in the quality of the learning experience. The researcher aims to determine whether a performance difference exists in students who used social media as an enabler of student engagement compared to students who did not use social media as an enabler of student engagement. To address this aim, the following question emerges:

1. Would student performance improve if social media is introduced as a student engagement tool?

The emerging hypotheses will be considered to enable the researcher in answering the research question:

1. $\mathbf{H}_{0}$ : There is no significant difference in the performance of a student who uses social media as a student engagement enabler.

2. $\mathbf{H}_{1}$ : There is a significant difference in the performance of a student who uses social media as a student engagement enabler.

The findings of this study will provide educators with vital information on the use of available technological tools for improved student engagement.

The reader can expect the article organised as follow: Section II reviews prevalent literature on student engagement as is found in related work. The considerations for the research methodology for this study are presented in Section III. Section IV presents and discusses the research results and conclusions along with the limitations of this study is presented in Section V. The article concludes with a reference list of work from scholars that apply to this study.

\section{LITERATURE REVIEW}

Social media is defined as a decentralised, platform-independent Web 2.0 tool that emphasizes active participation, connection, collaboration and content sharing among users 
(McLoughlin and Lee 2007). Lim See Yin et al. $(2014,178)$ define social media technologies as a portable Web-enabled tool of technology, which is accessible through platformindependent Web-browsers that place emphasis on digitised social activities for collaboration, communication and creativity. Rutherford (2010) argues that we can divide social media into three categories:

- Category one places emphasis on share and organizes content including YouTube, Flickr and Digg

- Category two emphasises the creation and editing of content including WordPress, Blogger and Wikipedia

- Social network sites like Facebook, Twitter and Snapchat act as online communities, fora where users can communicate with peers, sharing thoughts and activities.

$\mathrm{Hu}$ and Kuh (2001) describe student engagement as the efforts to commit educational activities that contribute directly to desired outcomes by students themselves. Trowler (2010) argues engagement is more than the ability to participate or commit - it requires feeling, sense-making and activity. The author concludes that some of the reasons to participate include engagement to improve learning. Drawing on the author, three dimensions to student engagement are proposed:

- Behavioral - engaged students "typically comply with behavioural norms, such as attendance and involvement and demonstrate the absence of disruptive or negative behaviour".

- Emotional - engaged students "experience affective reactions such as interest, enjoyment or a sense of belonging".

- Cognitive - students "would invest in their learning, would go beyond the requirements and would relish the challenge".

Kearns and Frey (2010) introduced a backchannel as "a network of out-of-class dialogues among students". WhatsApp is well suited for creating such "out-of-class" dialogue between students and teachers, as it enables informal and creative correspondences. It is important to understand how these technologies allow back channels and provide support for them. Essentially converting it into mainstream access channels instead of back channel access.

Stone and Logan $(2018,44)$ stressed that student interaction with a backchannel would 
increase their sense of connectivity. Within education, literature relating to the use of social media, like WhatsApp, indicates that these informal learning spaces support students in terms of connectedness, information sharing and the establishment of learning communities (O'Keeffe 2016). The quality of the student's experience is promoted.

\section{Related work}

Taylor and Parsons (2011) argue that student engagement has focused on increasing performance, and positive behaviours among other things. New educational curriculum and practice must involve - Interaction, Exploration, Relevancy, Multimedia and Instruction to engage students in learning (Taylor and Parsons 2011, 7). Interaction includes respectful relationships and interaction - both virtual and personal - which show to improve student engagement. These authors also note that learners today want to continuously connect and communicate and want an environment to facilitate such connections. They notice that students list three requirements that align to the idea of interaction: (1) learning by cooperation with each other and people within their group, (2) interacting with experts and expertise and (3) providing increased opportunities for discussions.

Rambe and Bere (2013) explored Mobile Instant Messaging (MIM) to determine its potential to foster digital inclusion among Information Technology (IT) students in third-year at a university of technology. WhatsApp did not substitute teaching but helped to expand academic consultation beyond the campus consultation time. They reported that WhatsApp allowed shy, less confident students to engage more productively. Online participation surpassed participation in the classroom while some students became more outspoken online because the platform offered democratic speech in search of knowledge, critical questions and practices of exchanging information. The position of the lecturer has been transformed from a teacher into a facilitator and mentor who provided guidance. The role of the student transformed from an information user to knowledge generators, collaborators, knowledge seekers/givers, critical thinkers and group leaders. It is worth noting that although the method promotes the peer-to-peer engagement of students in consuming, manipulating and interrogating the subject matter, it by no means undermines the importance of the lecturer, in fact it accentuates the necessity of a "knowledge owner" to ensure the quality of the curriculum offering is not compromised, but improved.

Coleman and O'Connor (2019) published a scoping study of the use of WhatsApp in medical education, explaining narratively how it was used and assessed as well as its theoretical considerations. A 5-stage scoping analysis model was used in a variety of online educational repositories using the word "WhatsApp" in all search areas, with two searches 
from February 2009 to February 2019. With a 3-stage research selection process only original English papers reporting original WhatsApp data have been included in medical education. The description of learning outcomes in the included studies was evaluated by using a 5-level model. Only 5 studies with a pre-defined curriculum reported level 2 while the majority reported level 1. They concluded that WhatsApp in medical education is common and convenient and that literature suggests it may also be effective as a medical learning tool.

Comparing WhatsApp with Facebook, Bouchnik and Deshen (2014) found that due to the option of private messaging and simplicity that WhatsApp contributed more to student usage. Stone and Logan $(2018,52)$ concluded that students benefited from using WhatsApp to build a sense of connectedness through their study and that this connectedness was not supported through formal learning spaces.

Lim See Yin et al. (2014) investigated the engagement of Social Media Technologies (SMT) for academic purposes in East Asia among undergraduate informatics students and found that there is no difference between informatics students and non-informatics usage. In their analysis, WhatsApp is the fourth highest type of SMT used for academic purposes. The number 1 perceived benefit of using SMTs for academic purpose is the enablement of information/knowledge sharing.

Mandernach (2015) propose various data collection methods to measure student engagement at a course and institutional level. Student engagement is a complex phenomenon that encompasses a range of components of the learning experience, equally varied is the range of data collection approaches available to gauge student engagement. The author proposes data collection methods that are mapped against strengths and challenges. Of importance are the teacher ratings of students which strengthen the evaluation of the alignment between student and teacher perceptions of engagement in the classroom but is challenged by the valid perception that may be limited to the more observable, behavioural indicators of student engagement. Conclusions to this study suggest that student engagement is an integral component of a successful learning experience

\section{RESEARCH METHODOLOGY}

In this article, the researcher chooses student performance and experiments as an approach. This was necessary to analyse changes in student performance by comparing datasets of students: (i) who did not make use of social media as engagement enabler during course delivery over a semester and (ii) who used social media as engagement enabler during course delivery over a semester. In this research, the performance of students at the end of a semester is evaluated. 
Data in the form of exam qualification marks were extracted from an IT course which forms part of a set of modules in a diploma programme at a UoT in South Africa. This mark is a compilation of various assessments throughout a semester and it determines examination qualification. Since secondary data was used, the data were anonymised for ethical reasons, quantitatively approached and stored separately as datasets with independent variables.

Students across two semesters were evaluated. WhatsApp as a social media tool was introduced in this course in semester two of an academic year to increase consultation time between lecturer and students and student to student engagement. This tool was added to test the impact on quality, student engagement, and assess if improvements was be achieved in performance.

Participation was voluntary and a group administrator role was assigned to the class representative. Not all students in semester two participated in this study since only 65 signed up to the WhatsApp group. All the students were encouraged to participate in this although it was not compulsory. The lecturer did not participate in group chats while present on campus to prevent the group chat from replacing face-to-face consultation, but students were allowed to chat on a peer-to-peer basis. Chats were monitored by the group administrator who also ensured compliance to the rules like:

- No requests are made to the lecturer on the group while the lecturer is on campus to encourage face-to-face engagement.

- All chats should be to the benefit of the group.

- No derogatory language allowed. Violation of this rule leads to expulsion from the group on a repeated rule break.

- $\quad$ English was the preferred language of communication to the benefit of all.

All the analysis in this study was implemented in $\mathrm{R}$. $\mathrm{R}$ is a programming language which scientists and researches use to conduct statistical analysis, data visualization and more. Analysis of the data is achieved by applying scripts and routines based on objects and operators supplied by R. It also contains a variety of production elements like plots, tables and summaries. Statistical analysis was done for the following reasons:

- A normality test: check the variations in distribution of the data sets. The data is to be considered a normal distribution, if a data set (when displayed as a graph), follows a bell-shaped curve centered around the mean where the average occurs. It must also 
adhere to the empirical rule that indicates the percentage of the data set that fall within (plus or minus) 1 to 3 standard deviations from the mean. (Ghasemi and Zahedias1 2012).

- Statistical analysis: this analysis includes mean, standard deviation, skewness and kurtosis. The definition of the measures used in this study include: (i) mean is an average of a variable in a dataset, (ii) standard deviation means how far from the normal, (iii) skewness is a measure of symmetry or the lack thereof and (iv) kurtosis is a measure of whether the data is heavy-tailed or light-tailed to a normal distribution.

- Independence means test: test for a difference of mean between the two unrelated datasets. This test evaluates whether the means for two independent groups are significantly different for each other.

Analysis in this research article includes a w-test (normality test), a statistical analysis and a $t$-test (independence means test).

\section{RESULTS}

In this section, the results are presented. Figure 1 provides an overview of the two datasets used in this research. Semester two had an increment of 31 (57.40\%) in population compared to the 54 students in semester one. The subject pass rate improved from 67 per cent to 84 per cent. Indicators in this analysis substantiate the conclusion of an improvement in pass rate in semester two. At the same time, a decrease is observed in the failure rate of this subject in semester two. The number of failures dropped from 18 to 14 students while the population increased from 54 to 85 , resulting in an even lower proportional failure rate.

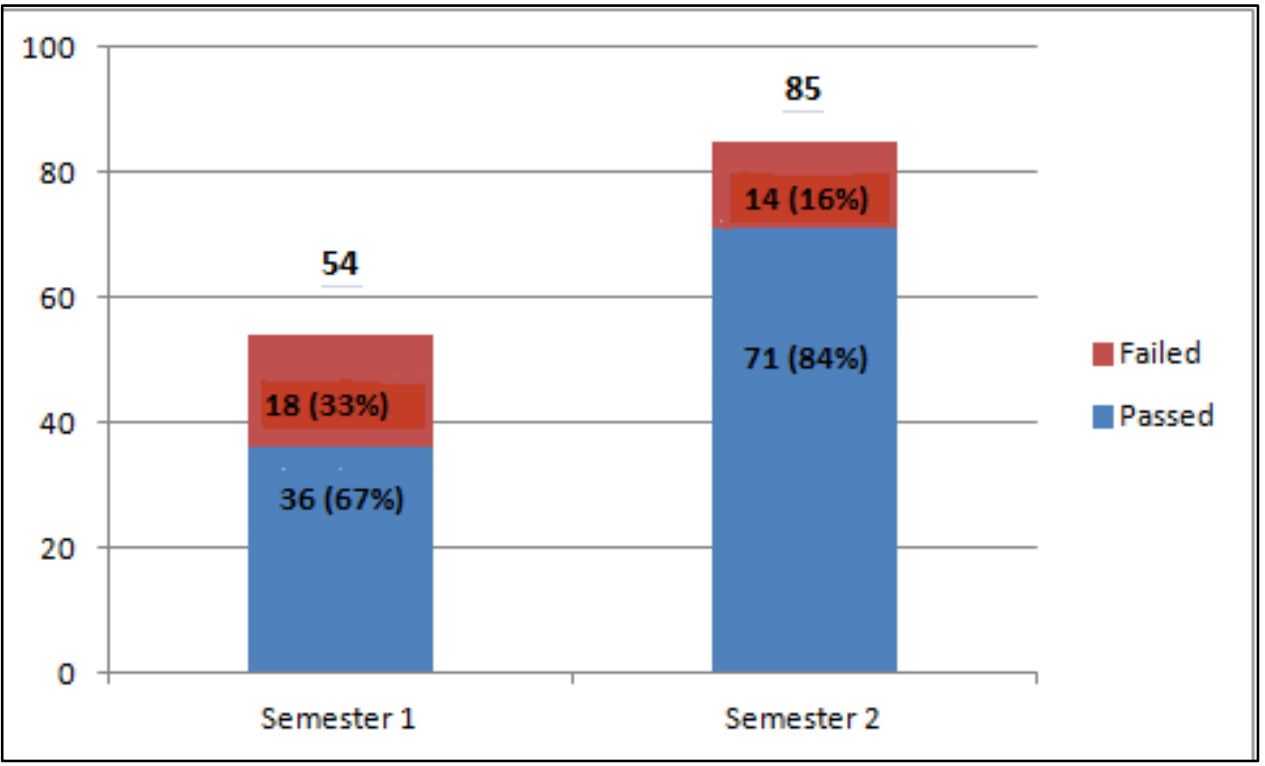

Figure 1: Overview of the population for semesters 1 and 2 
Figure 2 presents a histogram comparison of the marks of the two semesters. Both histograms emulate a data distribution with the bell curve incorporated in them. A high concentration around the mean is observed in semester one and the data appear more skewed to the right in semester two. This observed skewness is further interrogated and discussed later in the text. The spread of the semester one data ranges from 18 to 62 compared with a wider spread in semester two where the data range increased starting from 22 to 76 . Not only does the range of semester two start at a higher mark, but it also ends are much higher.
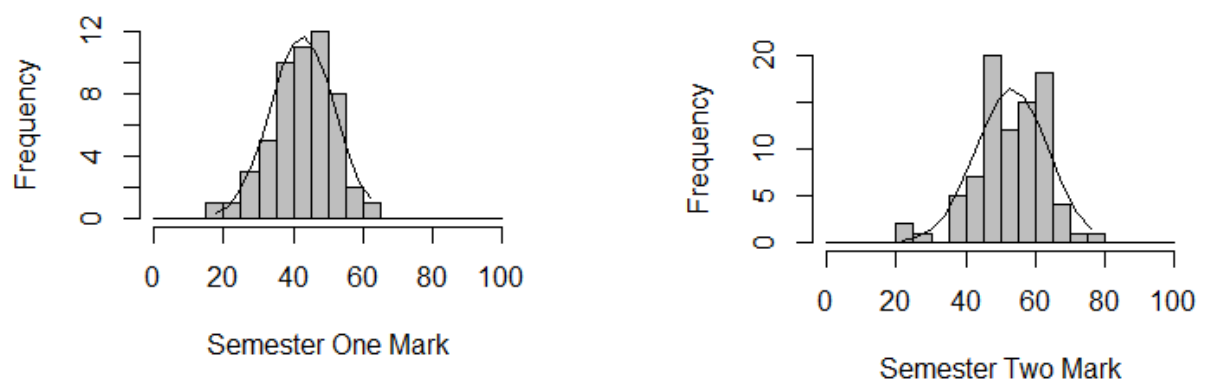

Figure 2: Histogram comparison

\section{Data test for normality}

The test for normality calculates the probability that a dataset was drawn from a normal population. The validity of data was tested with a w-test to establish the straightness of the quantile-quantile plot. Figure 3 gives a summary of the results of the w-test on the datasets as well as the QQ-plots of the two datasets. Alpha $(\alpha)$, which indicates significance level for these tests, is set at 0.05 . This is compared against the calculated p-value (measures the probability of getting a more extreme value than $\alpha$ ).

The $\mathrm{p}$-value of the semester one dataset is 0.5375 which is greater than alpha. This means that the assumption of data normality cannot be rejected. On the other hand, the p-value for the semester two dataset is 0.0328 , considerably less than alpha, therefore the assumption of data normality is rejected. Given these results it can be concluded that the data is normally distributed for semester one but not for semester two. At the same time, the distribution of the data points are on or near the linear regression line which supports the validity of the data distribution.

Figure 4 confirms the skewness in the datasets of semester one and two. The density graph for semester one indicated that the data have a measure of symmetry but semester two lack a measure of symmetry, favouring a positive skewness. 


\begin{tabular}{ll}
\multicolumn{1}{l}{ SEMESTER ONE } & \multicolumn{1}{c}{ SEMESTER TWO } \\
$\mathrm{W}=0.98085$, & $\mathrm{W}=0.9683$ \\
$\mathrm{P}-\mathrm{VALUE}=0.5375$ & P-VALUE $=0.0328$
\end{tabular}
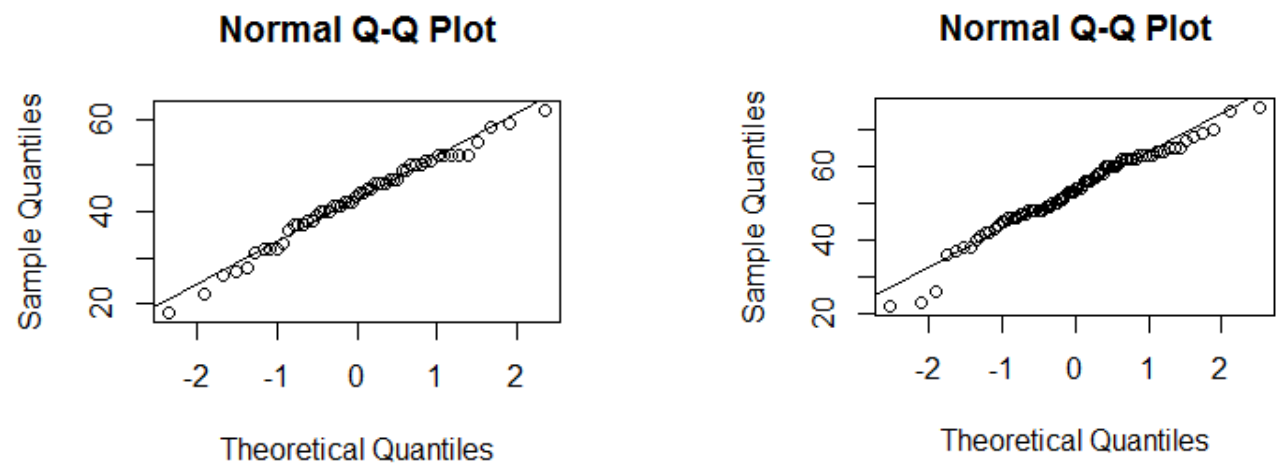

Figure 3: Data normality plot for semester one and two
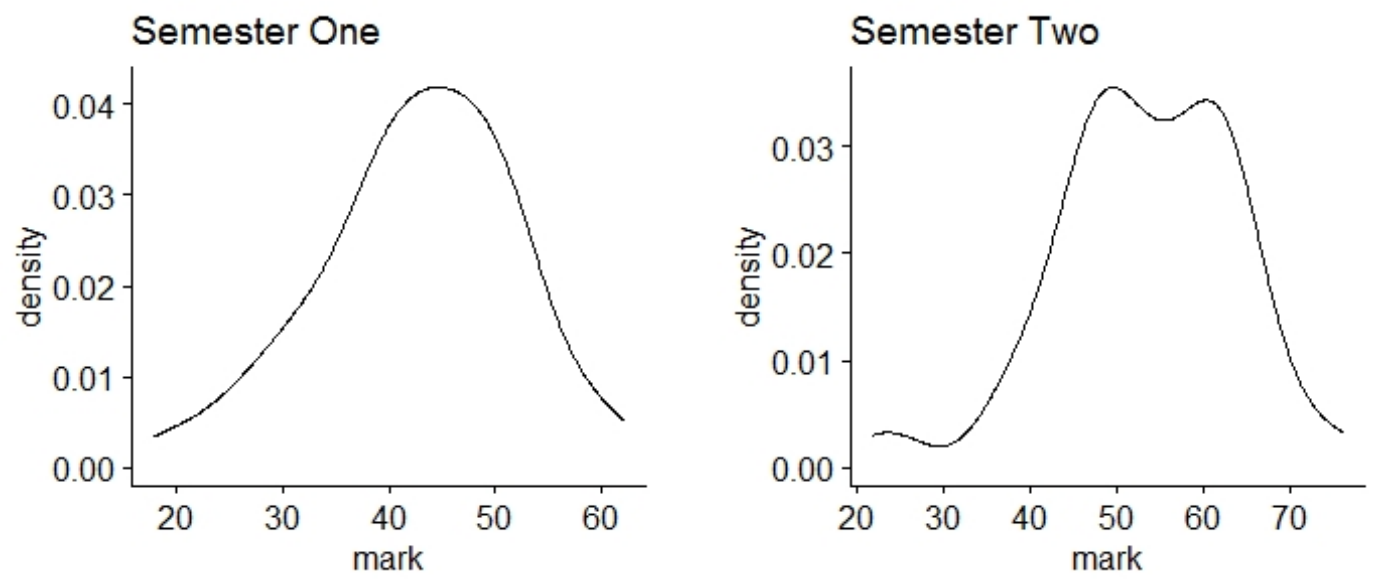

Figure 4: Density plots for semester one and two

\section{Statistical analysis}

An overview of performance between semester one and semester two is given in Table 1. The top-performing student was in semester two with a mark of 76 per cent compared to the top performer in semester one, who scored 62 per cent. The class average improved from 42.62 per cent in semester one to 53.23 per cent in semester two, an improvement of more than 10 per cent. The marks of students increased from an average of 53.23 with more than 10.44 marks in semester two. This means that there is a wider spread of marks in semester two compared to semester one, where the standard deviation is 9.24. An increase is observed in the measurement indicators of semester two students compared to the students in semester one.

Both the datasets have a negative skewness, however, the skewness in semester two is 
greater. This is as a result of the range (standard deviation) observed in the respective semesters. Semester one had a negative kurtosis indicating that the distribution is flatter than a normal data distribution and semester two have a positive kurtosis of 0.59 indicating a steeper curve compared to a normal distribution from a frequency perspective.

Table 1: Descriptive statistics of study samples

\begin{tabular}{|l|c|c|}
\hline Semester & One & Two \\
\hline Denominator & No social media usage & Social media usage \\
\hline Min & 18 & 22 \\
\hline Max & 62 & 76 \\
\hline Mean & 42.62 & 53.23 \\
\hline Standard Deviation & 9.24 & 10.44 \\
\hline Skewness & -0.42 & -0.55 \\
\hline Kurtosis & -0.05 & 0.59 \\
\hline $\mathrm{n}$ & 54 & 86 \\
\hline
\end{tabular}

\section{Independent means test}

The independent means test is an inferential statistic test that determines whether there is a statistically significant difference between means in two unrelated groups. For this reason, an independent means test was performed on the two populations to determine performance difference. A two-tail t-test was carried out between the means of the two datasets to establish the statistical significance of the two means.

Table 2 shows the outcomes for the hypotheses formulated earlier in this research study supporting the researcher's claim that the $\mathbf{M}_{1}-\mathbf{M}_{2} \neq 0$.

Table 2: Independent means test result

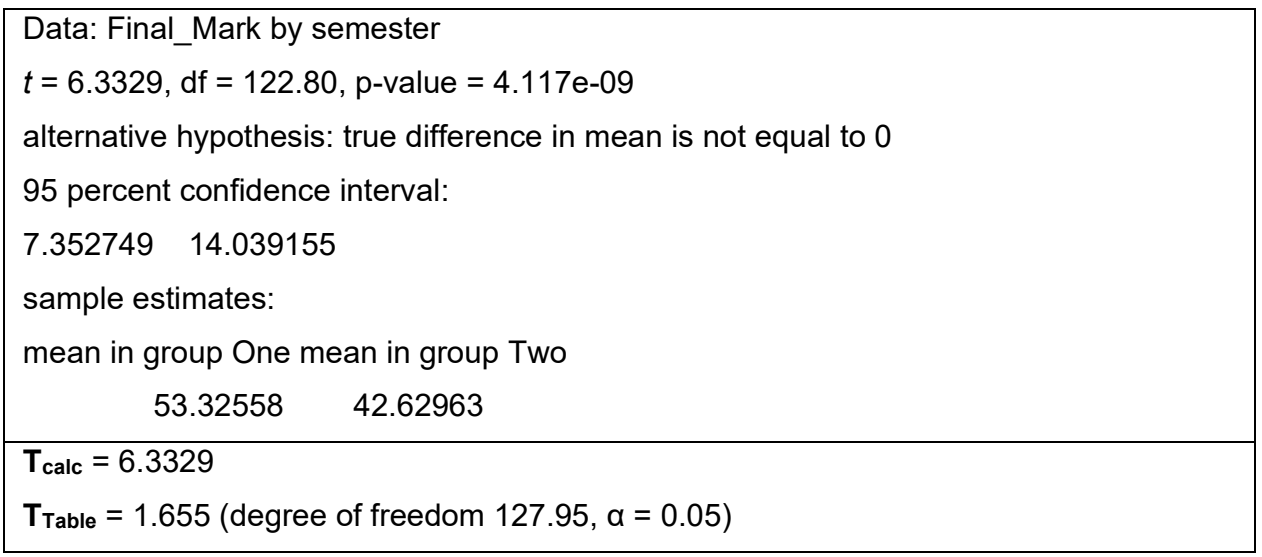

$$
H_{0}: M_{1}-M_{2}=0
$$

$H_{1}: M_{1}-M_{2} \neq 0$ (claim) 
Given that $\mathbf{T}_{\text {calc }}>\mathbf{T}_{\text {Table }}(6.3329>1.1655)$ and $p$-value $<0.05$, the $\mathbf{H}_{\mathbf{0}}$ is rejected in favor of

$\mathbf{H}_{1} . \mathbf{H}_{0}$ is rejected for two reasons:

1) the statistic lies in the rejection region of $>1.655$ and

2) there is sufficient evidence at $\alpha=0.05$ to suggest that there is a difference between the means of the two datasets (No social media and social media).

It is, therefore, valid to conclude that students who participated in WhatsApp to engage each other and the lecturer performed better than the students who did not engage each other and the lecturer.

\section{DISCUSSION}

This study interrogated the use of WhatsApp as an enabler for student engagement. In line with Mandernach (2015), this study attempted to address the behaviour observed that there was a low frequency of asking questions in class. This low participation in class could be ascribed to several reasons including shyness, peer-pressure, limited resources, etc. Adding to the inhibitors to engage in class was lecturer availability after class and finding time in the student's daily timetable. The introduction of WhatsApp as an SMT (Lim See Yin et al. 2014), was introduced as an enabler for student engagement (Coleman and O'Connor 2019) and that it can lead to maximized consultation time with peers and the lecturer during off-campus consultations (Rambe and Bere 2013). This not only strengthened the alignment between student and lecturer perceptions of engagement in class (Mandernach 2015, 4-5) but also allowed for off-campus consultation and resulted in better-engaged students. Improvement extended towards quality since SMT gave a voice to the withdrawn student without the pressure of raising matters in person. Feedback included areas where the lecturer could improve, an opportunity to ask questions, clarify concepts and share concerns regarding assignment submissions. The provision of an SMT resulted in students becoming active citizens (Zepke and Leach 2010,173) and students become more comfortable with the lecturer. This resulted in a higher performance, evident from the results of this study.

This study not only confirms findings in the literature regarding the improvement in performance of engaged students but indicates that SMT is useful as a backchannel for a dialogue beyond the limitation of on-campus consultation time. Furthermore, this study concurs with Taylor and Parsons (2011) and implies that engaged students achieve greater success in their studies. The researcher concludes that student performance shows reasonable improvement with the introduction of social media as a student engagement tool. Although 
the data show results at a specific university of technology and for a particular programme offering, this particular result cannot be transferred across disciplines and is not intended to show general outcomes. For this reason, the results are not to be considered as transferable without a preamble in rigorous study.

\section{Limitations}

Not all the students had smartphones to participate in this study, therefore the result cannot exclusively be ascribed to the introduction of WhatsApp as an engagement tool that contributes to student performance. However, it was a major contributor since the participating population represented 76 per cent of the class in Semester two and the content, environment and lecturer remained the same. A study over a longer period may be of benefit.

\section{Future study}

Student engagement is complex; it includes many factors that have a reciprocal relationship with each other. The incorporation of SMT into learner management systems should be investigated to enhance the student engagement at Institutions of Higher Learning.

\section{REFERENCES}

Bouchnik, D. and M. Deshen. 2014. WhatsApp goes to school: Mobile instant messaging between teachers and students. Journal of Information Technology Education: Research 13(1): 217-231.

Coleman, E. and E. O'Connor. 2019. The role of WhatsApp ${ }^{\circledR}$ in medical education: A scoping review and instructional design model. BMC Medical Education 19(1): 279.

Ghasemi, A. and S. Zahediasl. 2012. Normality tests for statistical analysis: A guide for nonstatisticians. International Journal of Endocrinology and Metabolism 10(1): 486.

Hu, S. and G. D. Kuh. 2001. Being (dis)engaged in educationally purposeful activities: The influences of student and institutional characteristics. Research in Higher Education 43(5): 555-575.

Kearns, L. R. and B. A. Frey. 2010. Web 2.0 technologies and backchannel communication in an online learning community. TechTrends 54(4): 41-51.

Kuh, G. D., J. Kinzie, J. A. Buckley, B. K. Bridges and J. C. ve Hayek. 2007. Piecing together the student success puzzle: Research, propositions, and recommendations. ASHE Higher Education Report 32(5).

Lim See Yin, J., S. Agostinho, B. Harper and J. F. Chicharo. 2014. The engagement of social media technologies by undergraduate informatics students for academic purpose in Malaysia. Journal of Information, Communication and Ethics in Society 12(3): 177-194.

Mandernach, B. J. 2015. Assessment of student engagement in higher education: A synthesis of literature and assessment tools. International Journal of Learning, Teaching and Educational Research 12(2).

McLoughlin, C. and M. Lee. 2007. Social software and participatory learning: Pedagogical choices with technology affordances in the Web 2.0 era. In ICT: Providing choices for learners and learning, ed. R. Atkinson, C. McBeath, S-K. A. Soong and C. Cheers, 664-675. Centre for Educational Development, Nanyang Technological University. 
O'Keeffe, M. B. 2016. Exploring higher education professionals' use of Twitter for learning. Doctoral dissertation, UCL (University College London).

Rambe, P. and A. Bere. 2013. Using mobile instant messaging to leverage learner participation and transform pedagogy at a South African University of Technology. British Journal of Educational Technology 44(4): 544-561.

Rutherford, C. 2010. Using online social media to support preservice student engagement. MERLOT Journal of Online Learning and Teaching 6(4): 703-711.

Stone, S. and A. Logan. 2018. Exploring students' use of the social networking site WhatsApp to foster connectedness in the online learning experience. Irish Journal of Technology Enhanced Learning Ireland 3(1): 42-55.

Taylor, L. and J. Parsons, 2011. Improving student engagement. Current Issues in Education 14(1).

Trowler, V. 2010. Student engagement literature review. The Higher Education Academy 11(1): 115.

Zepke, N. and L. Leach. 2010. Improving student engagement: Ten proposals for action. Active Learning in Higher Education 11(3): 167-177. 